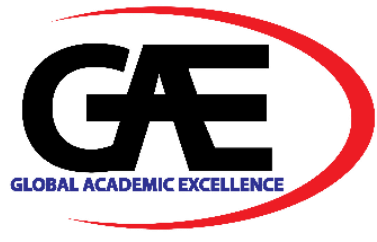

\title{
A PROPOSED THEORETICAL FRAMEWORK ON STRATEGIES FOR KLANG VALLEY MALAYSIAN QUANTITY SURVEYING CONSULTANCY FIRMS TO ACHIEVE PROFITABILITY
}

\author{
Bee-Ling Chong ${ }^{1,3^{*}}$, Kai-Chen $\mathrm{Goh}^{2}$, Tien-Choon Toh $^{3}$ \\ $1 \quad$ Faculty of Technology Management and Business, Universiti Tun Hussein Onn Malaysia \\ Email: hp160089@siswa.uthm.edu.my \\ Faculty of Technology Management and Business, Universiti Tun Hussein Onn Malaysia \\ 3 Lee Kong Chian Faculty of Engineering and Science, Universiti Tunku Abdul Rahman, Malaysia \\ Corresponding Author
}

\section{Article Info:}

Article history:

Received date: 13.07 .2020

Revised date: 10.08 .2020

Accepted date: 30.09 .2020

Published date: 01.12.2020

To cite this document:

Chong, B. L., Goh, K. C., \& Toh, T. C. (2020). A Proposed Theoretical Framework on Strategies for Klang Valley Malaysian Quantity Surveying Consultancy Firms to Achieve Profitability. International Journal of Law, Government and Communication, 5 (21), 01-12.

DOI: $10.35631 /$ IJLGC.521001.

This work is licensed under CC BY 4.0

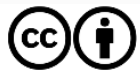

Abstract:

There is a lack of research studies showing the specific practices that enable QS consultancy firms to achieve profitability in Malaysia's construction industry. As firm profitability is expected to have a positive and significant impact on firm growth, this put Malaysia's QS consulting firms at risk and affected firm growth if the problem they face remains unresolved. Despite the current Covid-19 pandemic has led to the global financial crisis, weaker global growth is still a big issue to developing countries including Malaysia. Construction firms such as QS consultancy firms face a lot of challenges due to the globalisation and competitiveness of the construction industry. Quantity surveying (QS) consultancy firms need to adopt suitable strategies to survive and grow in an evolving business environment. Thus, this paper focuses on the theoretical framework of the strategies for QS consultancy firms.

Keywords:

Achieve Profitability, Quantity Surveying (QS) Consultancy Firms, Strategies, Theoretical Framework

\section{Introduction}

Today, the construction sector has become one of the major sectors of the Malaysian economy. Over the last two decades, it has been contributing between 3 to 5 per cent of the aggregate economy GDP. The construction boom in Malaysia began in the early 1990s, just after the launch of Vision 2020 (Khan, Liew, and Ghazali, 2014). Because of the significant roles and 


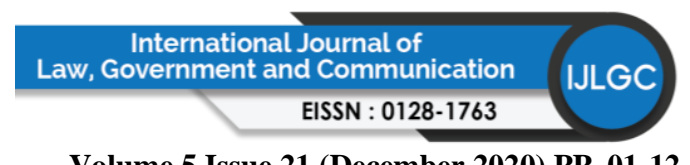

Volume 5 Issue 21 (December 2020) PP. 01-12 DOI 10.35631/IJLGC.521001

functions played by the construction industry, the Malaysia government has much emphasised on the growth of the industry and through Construction Industry Development Board (CIDB) Malaysia to develop the Construction Industry Master Plan (CIMP) to monitor the construction industry and solve the weaknesses from the year 2006 until 2015. While the Construction Industry Transformation Programme (CITP) was established to transform the construction industry to be highly dynamic, environmentally sustainable, with globally competitive players while concentrated on safety and quality standards from the year 2016 onwards.

According to Malaysia Productivity Corporation (2015), construction Professionals play essential roles in contributing to the domestic GDP. Professional services which are including the professional services to the building industry have been recognised for future growth. Surveying Services have been selected and identified as one of the focuses for future growth. This has shown the significance of the Surveyors in contributing to Malaysian economic development.

Wao and Flood (2016) described quantity surveyor had numerous roles in the construction industry, with most of them functioning as representatives of clients in construction projects. Chong, Lee, and Lim (2012) mentioned the QS profession in Malaysia has gradually developed due to the growth in volume and complexity of the building works over the last century. Since the essential role quantity surveyors play in construction, the Board of Quantity Surveyors Malaysia (BQSM) was set up. This statutory body is aimed to define the QS profession and to protect the rights and interests of registered QS accorded by The Act. Up to June 2020, there are 371 Quantity Surveying (QS) consultancy firms that were registered with BQSM; which were actively practised in the industry. This number covered small, medium, and big QS consultancy firms (BQSM, 2020). These numbers of QS consultancy firms are playing a significant role in Malaysia's construction business.

Nevertheless, all construction activities are slow down. According to the Department of Statistics Malaysia (2019), the construction industry from Quarter 1 (Q1) to Quarter 2 (Q2) in the year 2019 is growing slower than Q1 to Q2 in the year 2018. The value of construction work done in the second quarter of 2019 recorded a growth of 0.8 per cent year-on-year (Q1 and Q2 2019). This percentage of growth is lower than the year 2018 which is recorded a growth of 5.6 per cent in Q1 and Q2 of the year 2018. Currently, one of the important questions in business has been why some organisations succeeded in this turbulent market while others failed. The growth of the industry was declined seriously particularly the current Covid-19 pandemic has led to the global financial crisis. Weaker global growth is still a big issue for developing countries including Malaysia. Construction firms such as QS consultancy firms face a lot of challenges due to the globalisation and competitiveness of the construction industry. Moreover, a major shift is taking place in the construction industry with the advent of the fourth industrial revolution or IR 4.0, which will turn the construction industry in the direction of more digitally established trades. Managing a construction business is increasingly difficult. Personnel in the construction businesses depend deeply on specific skills, particular practice, technology preparation, and judgment based on experience which is enormously challenging to be automated (Alaloul et al., 2018). The survival and eventually the growth of the firms depend on the number or continuity of projects they secure without interval. QS consultancy firms need to respond to new opportunities, new geographical locations, and new ways of doing business (Davies, Gilbert, and Swartz, 2005). All construction players including QS consultancy firms may face difficulties to compete and survive in the emerging Copyright $\odot$ GLOBAL ACADEMIC EXCELLENCE (M) SDN BHD - All rights reserved 


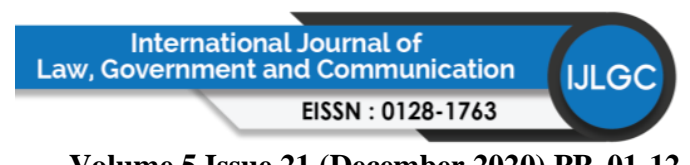

Volume 5 Issue 21 (December 2020) PP. 01-12 DOI 10.35631/IJLGC.521001

environment since there are intense competitions among themselves and from new or foreign entrants.

Therefore, QS consultancy firms need to adopt appropriate strategies to survive and grow due to this competitive and emerging business environment. Identifying strategies and their levels of significance in the firm is crucial in modelling strategies to QS consultancy firms to achieve the profitability in the competitive construction environment especially Malaysia's construction sector is recorded grow slower in the current Covid-19 pandemic. Nevertheless, it is difficult to select suitable strategies that would increase profitability as there are simply too many strategies available for implementation. Hence, this research is conducted to observe as many strategies as possible and then found a few significant strategies as possible to ensure manageability. The research findings will give a more complete view of the strategies for QS consultancy firms and the improvement to achieve profitability. Academics and practitioners could benefit from this study by applying suitable strategies and investigating in-depth for the strategies.

\section{Literature Review}

\section{Definitions of Profitability}

The word profitability is composed of two words, namely, profit and ability (Tulsian, 2014). Profitability is defined by Pandey (1980) as the ability of a business, whereas it interprets the term profit concerning other elements. Based on the Cambridge Dictionary (2019), profitability means the fact that something produces or is likely to produce a profit. In terms of Business English, Profitability is defined as the situation in which a company, product, etc. is producing a profit. Moreover, Oxford Learner's Dictionaries (2019) defined "profitability" is the ability to make a profit.

\section{Profitability and Growth}

Kithii (2008) as cited in MD Yusoff (2017), profitability is a key measure of a successful business. A business that is not profitable may not survive while a highly profitable business could reward its owners with large returns on their investment. While referring to Reynaud and Thomas (2013), the profitability of a firm is a highly complex concept ), as it results from firms' decisions on investment and production plans, but also constraints beyond their control such as economic regulation, level of competition, economic growth, etc.

Yazdanfar and Öhman (2015) indicated the firm profitability significantly and positively affects firm growth. Nevertheless, there is a very little research study on the relationship between profitability and growth. Therefore, it is necessary to conduct this study to find out the link between and the implication towards a firm's success.

\section{QS Consultancy Firms in Malaysia}

A Quantity Surveyor is a construction project consultant working in the construction industry who concerns with construction costs and contractual administration. Quantity Surveyors advise architects and engineers on the cost implications of their design, ensuring the clients' interests are always safeguarded (Tan and Yeoh, 2012). BQSM (2020) stated the QS profession in Malaysia is governed by the Quantity Surveyors Acts Amendment 2015. The "Quantity Surveyors (Amendment) Act 2015" is the latest amendment act. The final revision took effect on 30th January 2016. Currently, there are more than 370 QS consultancy firms in Malaysia. 


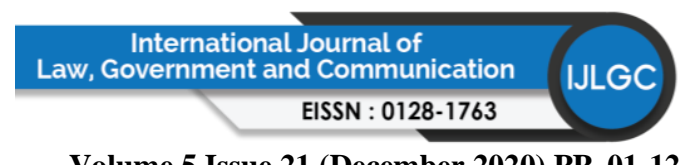

Volume 5 Issue 21 (December 2020) PP. 01-12 DOI 10.35631/IJLGC.521001

\section{Challenges to QS Consultancy Firms}

Nowadays, construction firms such as QS consultancy firms face a lot of challenges due to the globalisation and competitiveness of the construction industry. In the early days of century year, Page, Pearson, and Pryke (2004) had reported traditional services such as tender documents, tender appraisals, valuation, and preparing and agreeing final accounts have been the backbone of income for the majority of QS practices. These services are the traditional technical and professional services offered by quantity surveyors for many years.

However, there has been an improved move towards a one-stop, incorporated philosophy in the delivery of the construction. Turn down in the use of the traditional method of procurement presents certain challenges for the QS profession. The QS sector has not stood still during this period of revolution. The profession has moved towards developing new services with a focus on risk management, value management, legal and environmental services. The development of these has been a response to changes demanded by the major procuring clients.

When coming to the recent decade, there are getting more and more challenges are encountered by QS practices. Zainon et al. (2018) opined 5-dimensional (5D) of Building Information Modeling (BIM) has sparked a new technique of working in QS practice, transforming the traditional functions of a Quantity Surveyor. This modelling technology helps to save the time of QS in implementing their work and enhances the efficiency of work. The development and deployment of other technologies supporting the success to date are pushing towards IR 4.0.

The study conducted by Alaloul et al. (2018) provides clear evidence that the construction industry is doing more than its bit, generating and championing the use of those digital methodologies. The services provided by the profession are no longer restricted to traditional types anymore. New services and greater competition from within and outside of the QS profession demands a more effective approach to marketing. Thus, appropriate strategies are necessary to be adopted to QS consultancy firms for achieving profitability and ultimately lead the firm to success.

\section{Strategies for QS Consultancy Firms to Achieve Profitability}

The studies on strategies to achieve profitability have been the main interest or concern to many construction firms. To overcome the challenges, firms need to implement appropriate strategies to maximise the profitability of a firm and lead the firm to success. This sounds easy but it is difficult when to practice it by selecting the appropriate ones. Some previous research studies had been investigated the strategies and practices for construction professionals to achieve profitability.

In a study conducted by Li and Ling (2012), the theoretical framework used to study the practices and critical strategies implemented by Chinese architectural, engineering, and construction $(\mathrm{A} / \mathrm{E} / \mathrm{C})$ firms in China to maximise sale and profit are underpinned by three concepts: Generic competitive strategies, Military strategies: Sun Tzu's Art of War and Network strategies. The authors reported that profitability could be achieved by some critical practices which are underpinned in these three (3) strategies. They found that profitable Chinese $\mathrm{A} / \mathrm{E} / \mathrm{C}$ firms are more likely to implement practices that differentiate them from competitors instead of pursuing a focus strategy or low-cost strategy. Moreover, the practices that can make them more flexible and adaptable also on their list. Furthermore, profitable firms 


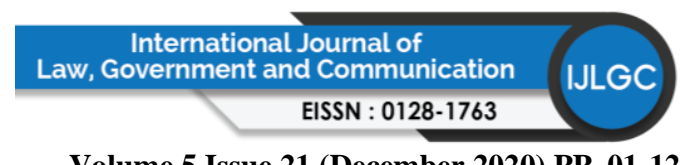

Volume 5 Issue 21 (December 2020) PP. 01-12 DOI 10.35631/IJLGC.521001

also implement practices that involve partnership, knowledge sharing, and gaining resources from firms in the network.

While in Hong Kong, Shen and Chung (2007) recommended that the QS profession must recognise the importance of Information Technology (IT) and take appropriate actions to meet the challenges of an ever-changing and competitive marketplace. When coming to United Kingdom (UK), the 'Building Information Modelling' (BIM) is one of those developments that have drawn major interests in the UK construction industry with considering recent technological advancements over the decades especially with IT, the UK government has acknowledged this trend and is entering the essential movement of implementing BIM by also making it a prerequisite for all those involved in public sector projects to have BIM ready by the year 2016. For the QS profession, BIM shows enormous challenges and opportunities, especially in cost estimating and quantity take-off which is a process that traditionally is very time consuming for quantity surveyors. BIM presents the ability to automatically produce quantity take-offs and measurements precisely from a digital model of a building (Wu et. al., 2014).

Besides the above strategies, Ogbu (2015) urged the application of Marketing Strategies in Nigerian Quantity Surveying (NIQS) firms is necessary to improve firm performance. He stated the implementation of marketing strategies in QS firms is a key management tool for the achievement of firm performance. He recommended NIQS to develop their marketing strategies that can lead to the achievement of firm performance.

\section{Generic Competitive Strategies}

In a few decades ago, Porter (1980) suggested that a firm needs to adopt generic competitive strategies - overall low-cost, differentiation, and focus to succeed in business. A firm can enhance its competitive stance by lowering its production and marketing costs with the overall low-cost strategy. At the same time with the differentiation strategy, a firm must be unique by offering exclusive services and unique products that are widely valued by customers to differentiate itself from others. A firm would have a strategic advantage with the focus strategy. A firm can narrow its competitive scope in the industry and modifies its strategy to serving to the exclusion of others, instead of serving broadly in the market.

Jennings and Betts (1996) later researched by using IT as a competitive strategy for PQS practices in the UK. IT does appear to be vital for all competitive strategies when combined with the skills and knowledge base of the human resources within PQS practices and the successful design/redesign of core processes even the use of IT by the QS profession is shown to be limited to supporting or enhancing competitive strategy rather than creating it. Then, Tansey, Spillane, and Meng (2014) supported that Porter's model is a well-known theoretical framework among business strategists and industrial economists worldwide. The analysis in their study provides strong support for the adoption of cost leadership strategies to surviving the 2007 economic recession.

\section{Military Strategies: Sun Tzu's Art of War}

According to McNeilly and McNeilly (2012), Sun Tzu's principles are ideally suited to today's competitive modern business situation. Sun Tzu's appeal has extended beyond the military realm into the war of business. They proposed six Sun Tzu's principles into practice. The six principles, namely win all without fighting: achieving the objective without destroying it; avoid Copyright (C) GLOBAL ACADEMIC EXCELLENCE (M) SDN BHD - All rights reserved 


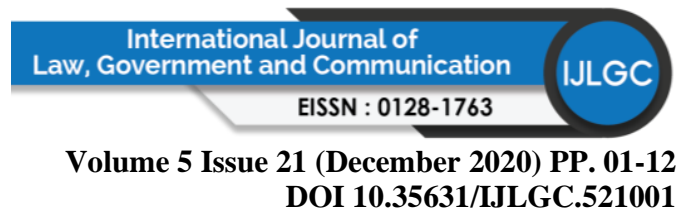

strength, attack weakness: striking where the enemy is most vulnerable; deception and foreknowledge: maximising the power of market information; speed and preparation: moving swiftly to overcome resistance; shape your opponent: employing a strategy to master the competition, and character-based leadership: providing effective leadership in turbulent times. A firm may succeed in the business to adopt these six strategic principles due to the 'flexibility' of these principles.

\section{Network Strategies}

In Chinese, Guan xi is a general term for social networking and is often translated as "relationship" or "connection". Guan xi was the one item that was consistently chosen by the respondents as a key success factor in the long-term business based on Yeung and Tung (1996). Wong (2007) found that guan xi plays the important role in setting the rules in doing business in Chinese society.

Moreover, Ling and Li (2012) highlighted the A/C/E firms should consider social network strategy besides just implement project management strategies. When managing projects in China, A/E/C firms need to set up networks purposefully and then go about developing these relationships. It is recommended that $\mathrm{A} / \mathrm{E} / \mathrm{C}$ firms consider the social network strategy and its accompanying practices identified in this study to help them in managing projects in China. Badi, Wang, and Pryke (2017) also underlined the high degree of structural and social embeddedness in Chinese Small Medium Enterprises (SMEs) with Guanxi bonds (both strong and weak) dominating the construction business-owners' network.

\section{Marketing Strategies}

Low and Kok (1997) stipulate Marketing should be a crucial element in the building and maintenance of a rewarding and profitable professional QS practice. However, many quantity surveyors have misinterpreted what marketing is all about. Several measures need to be taken to achieving marketing orientation calls. The measures are namely; top management support, effective organisation design, in-house marketing training, and improved personnel practices.

Furthermore, Ogbu (2015) states suitable marketing tactical strategies should be adopted in the execution of the firm's marketing campaign. Marketing strategies should be aimed at gaining higher firm performance in both financial and non-financial metrics. QS firms should understudy the relationship between their marketing activities and their organisational performance. Three groups of tactical strategies were suggested in his paper: people/organisational strategies, promotion and education strategies, and Price and other user outlay Strategies.

\section{Previous Research and Proposed Theoretical Framework}

\section{Previous Research}

There are increasing studies focused on the topic of profitability and strategies such as the "profitability" in the construction industry (Chiang, Chan and Hui, 2002; Makori and Jagonga, 2013), "critical strategies" for architectural, engineering, and construction (A/C/E) firms in China's construction industry to achieve "profitability" (Li and Ling, 2012), application marketing "strategies" in Nigerian quantity surveying (QS) firms (Ogbu, 2015) and "strategies" for the "profitability" in other fields (Lawrence et al., 2019; Gandy, 2015). However, very little 
work is found on the evaluation of interactions between productivity, strategies, and more specifically, in QS consulting firms.

The gap in knowledge is that hitherto, there are no studies to demonstrate the specific practices that enable QS consultancy firms particularly in the Klang Valley of Malaysia to achieve profitability. Strategies for QS consultancy firms to survive are not well established. As a result, this research will be undertaken to identify the specific practices that QS consultancy firms to adopt to achieve profitability in this competitive market.

\section{The Proposed Theoretical Framework}

A theoretical framework for this study is proposed and the summary table of strategies as showed on the next page. Figure 1 presents the theoretical framework for this research study. Generic competitive strategies, Military strategies: Sun Tzu's Art of War, Network strategies, and Marketing Strategies are the independent variables. These strategies are proposed to be implemented to achieve profitability. These strategies will be placed in a structured questionnaire with the five-point Likert scale $(1=$ strongly disagree, $2=$ disagree, $3=$ neutral, $4=$ agree, and $5=$ strongly agree) in each statement. The target respondents will be required to rate every statement to find out which ones are significant strategies. At the same time, the firm's capital growth, the firm's effectiveness, and the firm perceive low risk are the dependent variables. These are the immediate effects after achieving profitability. Ultimately, the identified significant strategies will lead the firm to success. 


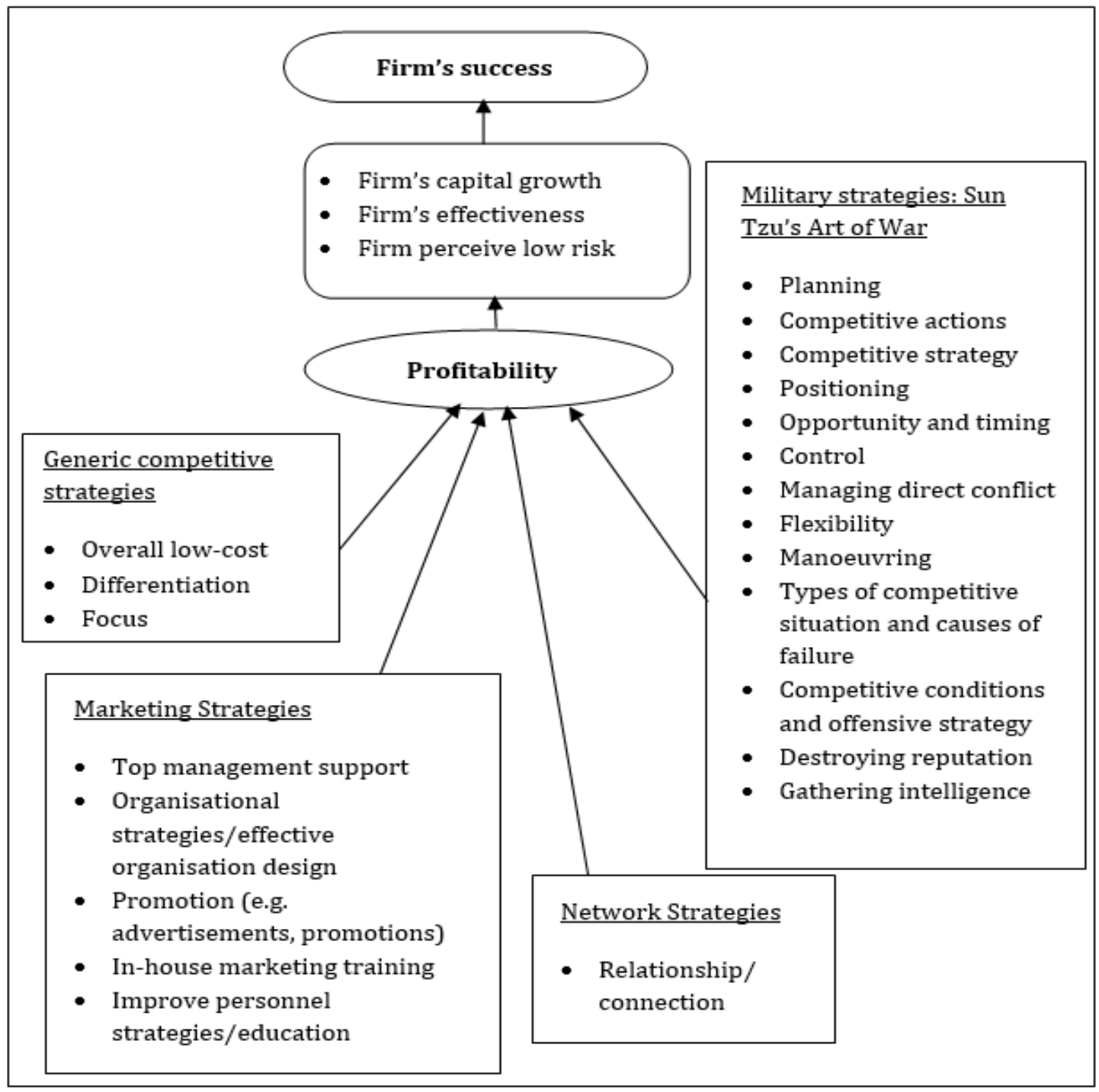

Figure 1. Schematic Diagram of The Theoretical Framework on The Strategies for QS Consultancy Firms to Achieve Profitability

\section{Research Methodology}

A structured questionnaire will be prepared based on the proposed theoretical framework and to be distributed to the appropriate respondent groups. In this study, the structured questionnaires will be sent out to the directors of QS consultancy firms in Klang Valley to obtain the perceptions of the quantity surveyors from a small, medium, and large size consultancy firms toward the extent of the strategies identified from the literature review to achieve profitability in their organisations. Klang Valley consists of the area in the centre part of the State of Selangor, Malaysia. It includes the capital of the country: Wilayah Persekutuan Kuala Lumpur (WPKL) and its neighbouring towns and cities naturally delineated by hilly areas and the Port Klang coastline. Klang Valley is selected as the place for researching because this central region of Peninsular Malaysia is the heartland of Malaysia's industries and the majority of firms headquartered in this area by referring to BQSM website (BQSM, 2020). There is no formal list of all the QS consultancy firms operating in Malaysia. Hence, QS 


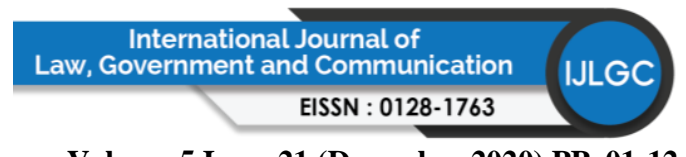

Volume 5 Issue 21 (December 2020) PP. 01-12 DOI 10.35631/IJLGC.521001

consultancy firms operating in Selangor and WPKL (Klang Valley) which are members of the Board of Quantity Surveyors Malaysia (BQSM) will be chosen as subjects for this research. Based on BQSM website, there are 245 registered consultant QS firms in Klang Valley out of 374 firms. The target respondents who are selected from BQSM website are requested to rate the questionnaire and give any necessary comments in the open question. The questionnaire allows the respondents to provide other strategies that are not integrated into the survey but are perceived to have some degrees of influence on QS firm's profitability through the one open question in the questionnaire.

Mean ranking, exploratory, and confirmatory factor analyses, and structural equation modelling will be used in the data analysis stage. Firstly, reliability analysis adopting the internal consistency method is carried out to make sure that a rating scale of 1 to 5 employed in measuring strategies would yield a similar result over time. After that, Factor analysis is an exploratory technique used to summarise the structure of a set of variables. If possible, the overall sample size should be more than 150 , and that the ratio should be at least five cases for each of the variables. Also, to be considered suitable for factor analysis, the correlation matrix should show some correlations of $r=0.30$ or greater. Bartlett's Test of Sphericity has to be statistically significant at $\mathrm{p}<0.05$ and the Kaiser-Meyer-Olkin Measure of Sampling Adequacy (KMO) value should be 0.60 or above. Partial least squares structural equation modelling (PLS-SEM) is selected and used in this study because this study is meant to identify the exploratory factor analysis of significant strategies. At last, this tool will develop a structural equation model of strategies to explain causal relationships among strategies groupings by using the SmartPLS3.0 statistical software.

In summary, quantitative data collected using a five-point Likert scale for this study are analysed statistically by using the PASW Statistics 18 and SmartPLS 3.0. In the end, a structural equation modelling of strategies groupings that are practical in guiding the implementation or execution of a construction business in Klang Valley, Malaysia is developed to be used by professional service firms.

\section{Recommendations For Future Work}

This study aims to develop a structural equation modelling (SEM) with the technique of partial least squares (PLS) for underlying the strategies for QS consultancy firms in assisting them to achieve the profitability, bring the capital growth and effectiveness to the firm then firm perceive low risk and ultimately lead them to firm's success. Generic competitive strategies, Military strategies: Sun Tzu's Art of War, Network strategies, and Marketing Strategies are found as the independent variables from the literature review. At the same time, the firm's capital growth, the firm's effectiveness, and the firm perceive low risk are the dependent variables. These are the direct consequences after achieving profitability. The findings of this study are expected to comprise the ranking of strategies, identification of latent strategies, and development of a structural equation model of latent strategies for QS consultancy firms to achieve profitability.

Nevertheless, the scope of this study is specified and limited. As a result, future studies could be carried out by (1) reproducing the current study at other places; (2) adding newly known strategies into the current study; and (3) conducting the similar research for other types of organisation such as contractor, developer, the civil engineering company, etc. 


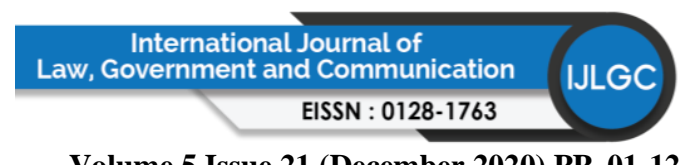

Volume 5 Issue 21 (December 2020) PP. 01-12 DOI 10.35631/IJLGC.521001

Due to it helps validate the outcome of the previous study, reproducing is frequently encouraged in doing research. Hence, future researchers could replicate the current study employing data gathered from other places. For example, the survey can be done in other locations within Malaysia including Johor Bahru, Penang, Ipoh, Kuching, and Kota Kinabalu since these are the major developing cities in the country. This could provide an overall view of strategies to achieve profitability at the national level.

Additionally, future researchers could consider some of the newly known strategies since there are getting more and more recent publications about this topic in the future. More recent literature will be adding more newly discovered in the present list of strategies. Furthermore, it would be interesting to figure out the present list of strategies whether suitable to organisations like contractor, developer, and civil engineering company or not. Different types of organisation or environment might have different perceptions and the significant difference.

\section{Conclusion}

Throughout this study, QS consultancy firms will be requested to consider the significant strategies which help them when they are attempting to achieve their profitability. Maximise the profit is the common target in the construction industries worldwide but the firm able to produce a return on an investment based on its resources is a question. Therefore, the strategies for QS consultancy firms must be identified in the first place. For that reason, this research will be conducted to reveal the significant strategies groupings pertinent to the QS consultancy firms in the Klang Valley of Malaysia.

Seeing that understanding of the interrelationships among strategies groupings for QS consultancy firms will be able to provide a clear direction in maximising profit and increasing the business; this research has then developed a structural equation model to explain causal relationships among strategies grouping. Ultimately, this research could inform practitioners of the best strategies that would improve profitability. Foreign and new QS consultancy firms that intend to venture into the Klang Valley Malaysian construction industry may also use the findings to assist them to expand and develop their businesses in this sector.

\section{References}

Alaloul, W. S., Liew, M. S., Zawawi, N. A. W. A. \& Mohammed, B. S. (2018). Industry Revolution IR 4.0: Future Opportunities and Challenges in Construction Industry. MATEC Web of Conferences 203, $1-7$.

Badi, S., Wang, L., \& Pryke, S. (2017). Relationship marketing in Guanxi networks: A social network analysis study of Chinese construction small and medium-sized enterprises. Industrial Marketing Management, 60, 204-218.

BQSM (2020). World Wide Web. Retrieved on June 28, 2020, from https://www.bqsm.gov.my/index.php/en/

Cambridge Dictionary (2019). World Wide Web. Retrieved on June 28, 2019, from https://dictionary.cambridge.org/dictionary/english/profitability

Chiang, Y.H., Chan, P.C. \& Hui, Eddie, C.M (2002). Capital structure and profitability of the property and construction sectors in Hong Kong. Journal of Property Investment \& Finance, 20(6), $434-453$.

Chong, B. L., Lee, W. P. \& Lim, C. C. (2012). The Roles of Graduate Quantity Surveyors in the Malaysian Construction Industry. International Proceedings of Economics Development \& Research, 17 - 20. Singapore: IACSIT Press. 


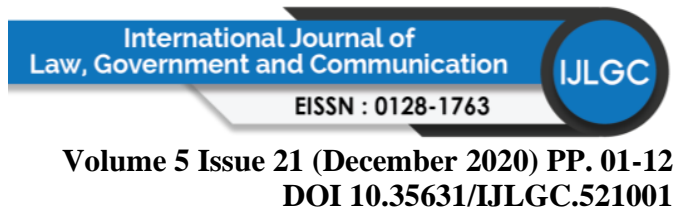

Davies, T. Gilbert, B. \& Swartz, J. (2005). Competitive response: A new lens for evaluating company performance. In the Practical Real-Time Enterprise. Berlin: Springer Berlin Heidelberg, $57-69$.

Department of Statistics Malaysia (2019). Quarterly Construction Statistics, Second Quarter 2019. Retrieved August 15, 2019, from https://www.dosm.gov.my/v1/index.php?r=column/cthemeByCat\&cat=77\&bul_id=U XIZVXpFVIVVK1BHWHM3TENvTGZQZz09\&menu_id=OEY5SWtFSVVFVUpm UXEyaHppMVhEdz09

Gandy, D. L. (2015). Small Business Strategies for Company Profitability and Sustainability. Walden Dissertations and Doctoral Studies.

Jennings, M. J., \& Betts, M. (1996). Competitive strategy for quantity surveying practices: the importance of information technology. Engineering, Construction and Architectural Management, 3(3): 163 - 186.

Khan, R. A., Liew, M. S., \& Ghazali, Z. B. (2014). Malaysian Construction Sector and Malaysia Vision 2020: Developed Nation Status. Procedia - Social and Behavioral Sciences, 109: 507 - 513.

Kithii, J.N., (2008). The relationship between working capital management and profitability of listed companies in the Nairobi Stock Exchange. University of Nairobi: Master's Thesis.

Lawrence, J. M., Crecelius, A. T., Scheer, L. K., \& Patil, A. (2019). Multichannel Strategies for Managing the Profitability of Business-to-Business Customers. Journal of Marketing Research, 56(3), $479-497$.

Li, S. \& Ling, Florence, Y.Y. (2012). Critical strategies for Chinese architectural, engineering and construction firms to achieve profitability. Engineering, Construction and Architectural Management, 19(5), 495 - 511.

Ling, Florence, Y. Y., \& Li, Shan. (2012). Using social network strategy to manage construction projects in China. International Journal of Project Management, 30(3), $398-406$.

Low, S. P., \& Kok, H. M. (1997). Formulating a strategic marketing mix for quantity surveyors. Marketing Intelligence \& Planning, 15(6), $273-280$.

Makori. M. and Jagongo, A. (2013). Working Capital Management and Firm Profitability: Empirical Evidence from Manufacturing and Construction Firms Listed on Nairobi Securities Exchange, Kenya. International Journal of Accounting and Taxation, 1(1), $1-14$.

Malaysia Productivity Corporation (2015). Regulatory Review Final Report: Professional Services to The Construction Industry. Retrieved on June 27, 2020, from http://www.mpc.gov.my/wp-content/uploads/2016/05/Professional-servicesREPORT-04b_Final-Draft-Report.pdf

McNeilly, M. \& McNeilly, M.R. (2012). Sun Tzu and the Art of Business: Six Strategic Principles for Managers. New York, Oxford University Press, 329 pp.

MD Yusoff, H. B. (2017). The Effect of Liquidity and Solvency on Profitability: The Case of Public-Listed Consumer Product Companies in Malaysia. Master Thesis, Universiti Tun Hussein Onn Malaysia, 97 pp.

Ogbu, C. P. (2015). Application of Marketing Strategies in Nigerian Quantity Surveying Firms. Journal of Economics and Sustainable Development, 6 (16), 1 - 20.

Oxford Learner's Dictionary (2019). World Wide Web. Retrieved on June 28, 2019, from https://www.oxfordlearnersdictionaries.com/definition/english/profitability 


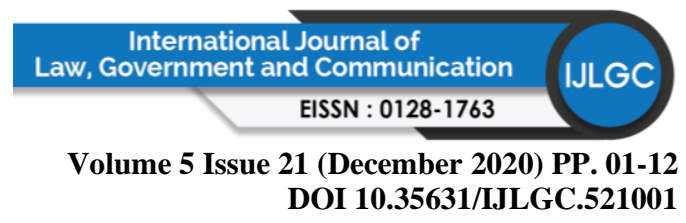

Page, M., Pearson, S. and Pryke, S. (2004). Innovation and current practice in large UK quantity surveying firms. RICS Foundation Research Paper Series, 4 (25), 1 - 24.

Pandey, I. M. (1980). Concept of Earning Power. Accounting Journal, Vol. IV.

Porter, M. E. (1980). Competitive Strategy: Techniques for Analysing Industries and Competitors. New York, Free Press.

Reynaud, A., \& Thomas, A. (2013). Firm's Profitability and regulation in water and network industries: An empirical Analysis. Utilities Policy, 24, 48 - 58.

Shen, Q. \& Chung, Jacky, K. H. (2007). The use of information technology by the quantity surveying profession in Hong Kong. International Journal of Project Management, 25 (2), $134-142$.

Tan, C. K. \& Yeoh, K. C. (2012). A Study on the Use of Measurement Software in the Preparation of Bills of Quantities among Malaysian Quantity Surveying Firms. 2011 Ninth International Conference on ICT and Knowledge Engineering, 53 - 58.

Tansey, P., Spillane, J. P. \& Meng, X. (2014) Linking Response Strategies adopted by construction firms during 2007 economic recession to Porter's generic strategies. Construction Management and Economics, 32 (7-8), 705 -724.

Tulsian, M. (2014). Profitability Analysis (A comparative study of SAIL \& TATA Steel). IOSR Journal of Economics and Finance, 3 (2), 19-22.

Wao, J. O., \& Flood, I. (2016). The Role of Quantity Surveyors in the International Construction Arena. International Journal of Construction Management, 1-12.

Wu, S., Wood, G., Ginige, K., \& Jong, S. W. (2014). A Technical Review of BIM Based Cost Estimating in UK Quantity Surveying Practice, Standards and Tools. Journal of Information Technology in Construction, 19, 534-562.

Wong, M. (2007). Guanxi and its role in business. Chinese Management Studies, 1(4), 257276.

Yeung, I. Y. M., \& Tung, R. L. (1996) Achieving business success in Confucian societies: The importance of guanxi (connections). Organizational Dynamics, 25(2), 54-65.

Yazdanfar, D. \& Öhman, P. (2015). The growth-profitability nexus among Swedish SMEs. International Journal of Managerial Finance, 11(4), 531-547.

Zainon, N., Mohd-Rahim, F. A., Aziz, N. M, Kamaruzzaman, S. N., \& Puidin, S. (2018). Catching up with Building Information Modeling: Challenges and Opportunities for Quantity Surveyors. Journal of Surveying, Construction and Property, 9(1), 19 - 31. 